\title{
Fuzzy Agent Oriented Software Effort Estimate with COCOMO
}

\author{
Mohammad Saber Iraji \\ Faculty Member of Department of Computer Engineering and Information Technology, Payame Noor University, I.R. \\ of Iran \\ E-mail: iraji.ms@gmail.com
}

\begin{abstract}
In software engineering is an important issue,predicates effort and schedule time for projects.In 1995 COCOMO 2 was introduced for modern software development processes .COCOMO 2 Is dependent on the program size in sloc and a set of cost drivers and Scale Factors given according to each phase of software life cycle. Defined by the agent, the agent-oriented software engineering is created a new development, was introduced as a new methodology in software engineering. The estimated cost of aspect oriented effort estimate is based on event, rule, goal, task, state machines features. We presented in This paper proposed approaches to reduce projects effort Mean Magnitude of Relative Error (MMRE) Than the actual amount for agent oriented software engineering, through Methods:Total sloc agent element,Total weighted sloc, Total pure fuzzy agent sloc,Total weighted fuzzy sloc, Total weighted fuzzy sloc *fuzzy element,Geometric mean For fuzzy sloc per item, Harmonic mean for fuzzy sloc per item, fuzzy combinatorial proposed system of elements density via determine the size of the three agent oriented projects And apply them to the COCOMO 2 model. Among the proposed approaches, fuzzy combinatorial proposed system of agent elements density are achieved better and more accurate results.
\end{abstract}

Index Terms - Agent, Fuzzy, Effort, Cost, Software Engineering, COCOMO

\section{INTRODUCTION}

In the early days of working with computer, software costs made up a small percentage of the total cost of computer systems and So the error in estimating the cost of software, Had relatively little impact. Today software is the most expensive component of any computer system, For example, in custom systems, a large error in the estimated effort costs can be as the difference between profit and loss. Excessive costs would be catastrophic for the software manufacturer.

The estimated cost and work will never be an accurate knowledge. Numerous variables - human, technical, environmental, political, can affect the final cost of the software and the work done to develop it. But, software project effort estimation can be made from a black art to a series of systematic steps that provide estimates with acceptable risk. Software project estimation is a form of problem solving and in most cases, an issue which must be resolved (ie software project cost estimation and users) is more complicated than it needed to pay it all at once. Therefore, we analyze the problem, and bring it into a series of smaller, more manageable issues and we use the various models and factors in any model to estimate the cost.

Some methods such as empirical models is used to estimate software cost, the most famous of them are COCOMO models. But there are many other models like putnam. These models do experiments on previous achievements to predict the same outcome cost .by the help of the cost of these tests, managers of software has estimated the costs, explanation of variables resemble the programmers expertise's Average, complexity of issues, lines of source code, records and accept other things [1].

Bohm suggested the original COCOMO model which have been Changed in the years to achieve a better result for the calculation of the estimated software cost. Currently, the developed method, is considered COCOMO2, we use this method in this article to estimate the costs.

according to the type of software in different methodologies such as traditional, object-oriented, aspect-oriented, agent-oriented, different factors is being used to estimate the cost, Which we use the agentoriented software method in this paper. In COCOMO 2, main element which affects the final costs is the size that evaluates the expressed results in sloc or ufp [1]. we use the sloc logic for Agent oriented projects used in this article.

sloc is influenced by several factors in its determination. a lot of work has been done to calculate the sloc value to reach the appropriate PM.

In this paper, we first talk about agent-oriented software and its emerging .

Then we pay attention to these three projects:P815, p907,PSI3 that have been considered in paper[1] as the base of the work and offer some explanations about concepts and performance of COCOMO 2, and finally by making fuzzy the obtained information with COCOMO 2 , for the three projects, we are trying to estimate more accurately the cost of an agent-oriented software.

The paper is organized in five sections. After the introduction Section I, Section II which also introduces the related works of agent oriented software cost estimate. Section II continues with agent and COCOMO definition in section III .

In section IV fuzzy models for proposed system and examples presented. Section V and VI presents the results, conclusions of the research. The paper ends with a list of references. 


\section{LITERATURE}

Nancy merco in seminar [5] defines the emergence of cost estimation software. She focuses on the analysis of COCOMO 1, COCOMO 2, and Effective and required items in cost estimation by the COCOMO and counts the disadvantages and defects of this method. He believes that, by adding the experimental results to this model the efficiency can be increased and ultimately According to the existing problems in COCOMO 2, he permits to use it in the fields of software project management.

Majed alyahya in [7], first has tried to describe COCOMO 2 cost estimation model and has made changes in the power size to improve this model,, where sf-butPMATJ can be replaced sf, he calculates it by the sum of 4 items TEAM,RESL,FLEX,PRES. Of course, the basis of COCOMO 2 costs estimate model theory is presented in $[15,17]$.

Professor Lotfi Zadeh presented fuzzy theory in Paper [4], which is contrary to the theory of binary logic and it brings out the binary logic from the situation that is completely true and false and gives more flexibility to it .

At [15], the authors have used the fuzzy set for COCOMO model81, Musilekp and others in paper [16] have used the fuzzy set for f-COCOMO model.

In paper [6] they have fuzzified COCOMO 2 model Using fuzzy logic. They used EMS,SF,SZ entries for fuzzifying COCOMO2 Where EMS includes 17 multiplicative factors in calculating PM, and SF includes 5 Accumulative factors in calculating $\mathrm{b}$, and $\mathrm{SZ}$ is the value of Sloc.

In paper [11] they have used Fuzzy Logic to offer cost estimate suggestion. They have used sugeno type with model input and size and variable effort output for fuzzifying COCOMO. Then to continue the work, they have applied two generalized triangle and bell membership functions, and they have compared Them with the original COCOMO model.

The authors In paper[8] attempted to estimate the cost of object-oriented software with neural and fuzzy. They introduced usp(use case size point), they used of uusp, fta, faa factors To obtain this index.

In [1] First, they tend to describe the three European research project For agent-oriented software cost estimation that the projects are excellent sources of information for obtaining results. Then they proceeded to review the basic concepts, such as sloc,ufp in COCOMO2 Metric Projects Management. in this paper a table of digits and numbers needed for the three projects is Presented that they used 7 items in sloc calculations According to the arguments presented in it . In this paper, two methods are proposed for calculating sloc. The results obtained in the $\mathrm{PM}$, months calculations were compared with actual cost and COCOMO That almost better results have been achieved.

In Article [2], as well as Article [1] They are trying to offer a solution to improve PM also they define three agent-oriented research projects and Effective factors in COCOMO 2. They define a new relationship, to determine the amount of sloc they Have Mentioned it as total sloc .by Multiplying the $b$ arithmetic items average in their Amount, and summation of them, they calculate sloc size to determine the PM. Then they compared The results obtained in this way to the traditional mode, and they achieved better results than the traditional mode. Total Sloc were calculated from equation 1, The event,rule,goal,task, state machines factors were considered To calculate the cost of an agent-oriented .

Total weighted Sloc $=\mathrm{A}_{\mathrm{E}} *(\# \mathrm{E})+\mathrm{A}_{\mathrm{R}} *(\# \mathrm{R})+\mathrm{A}_{\mathrm{G}} *$ $(\# \mathrm{G})+\mathrm{A}_{\mathrm{T}} *(\# \mathrm{~T})+\mathrm{A}_{\mathrm{S}} *(\# \mathrm{~S})$

Where $A_{E}$ is average event and $A_{R}$ is average rule and $A_{G}$ is average goal and $A_{T}$ is average task and $A_{S}$ is average state machines in sloc for 3 projects .

\section{DEFINITION}

\section{A. Agent Definition}

In $1990 \mathrm{Mr}$ yaushodham introduced a new concept in programming as agent that its definition was changed in 1993. Therefore, based on the Oxford Dictionary definition, an agent is a personal factor that is qualified to do something In one place with permission of another person.

Many people Have expressed the agent definition,One of the definitions that is provided by sofer is so:

Agent is stable software entity, which is designed to achieve a particular goal.

In computer science, a software agent is a piece of software which acts such as an agency in a relationship with a user, program or other agent.

Russell defines agent such this:Agent is a single computing unit such as software program or a robot, which is visible and it is connected to its environment and it is gained by experiences and adjusts its behavior and the and reacts to the environment and it is an autonomic. The Agents have some goals, which their actions are in order to reach them. Based on the According Russell definition, agents are divided into five floors of the classes according to the degree of intelligence and their features:

1 simple reflex agents

2 model based reflex agents

3 goal- based agents

4 utility-based agents

5 learning agents

The agent architecture has a decisive role in the specification and behavior of the agent. Types of agent architecture can be in one of the categories below.

1 Logical model that is symbolic, and uses the reasoning mechanism.

2 The interaction model that responds based on performing an action.

3 A layer model is a combination of the other models.

4 BDI(belief, desire, intention) has Mental structure, and is one of the most popular models.

Layered Architecture and BDI are the most famous using models in architecture that consider in Different methodologies. since factors operate in a common environment to reach a goal, they need a common 
language to understand each other.many companies and Institutions have operated to create agents dialogue Language and standard such as : ACL by FIPA or KQML and WSDL corporation .three tools that Agent-Oriented offers to the users to develop and manage Complexity, are: breaking, Abstraction and organization, by breaking the space of problem,complicated system breaks to agent parts and Communications,by Abstraction, agents seem appropriate for design and construction and the third case represents their efficiency for modeling and management of organizational relationships to reach dependencies and relationships inside the complicated system.

According to the above reasons, and also the other advantages of using multi-agent systems In solving engineering problems,such as :increasing reliability, extensibility, reuse, the possibility of parallel execution, the interaction of parallel systems, possibility of Implementation of Other field's Scientific theories, Agent-based complicated systems of software engineering,were introduced as the new guidelines in software engineering.

\section{B.Problem Definition}

as a source of information,we are using three European research projects which have been explained in article [1].these projects are not exactly like industrial projects, because their budget and time can't change and it's not expected to sell products of these projects.

Eures com p815: compilation of relationship management processes by using agent software : in this project agents help management applications of Workflows .our share is specified in these projects and agents run by helping of users and via the management of intelligent and dedicated service network's innovative environments. in these projects, the main subject is the interactions of agents for users and their ability to cooperate existing systems. at the end we implement two kinds of agents: Private management agents,(PMA) to help the management of projects and the private developer agent (PDA) to develop the projects.

Eurescom p907.message: a method for agent software engineering systems: the main results of this project are defined according to the message /uml method. to test this method,we design a helping path. in this implementation,there are three kinds of agents: helping private agent which states users in system and information finder agent which is responsible for searching information sources that is responsible for searching information sources related to the airport and the infoaena agent which covers airport information sources.

PSI3:private service`s interaction by agent software: this is an ACTS project that in this project we implement information of filtering systems as a group. these systems try to create virtual societies for users which every user registers and just receive interesting information. every user in system is exposed via an agent which is aware from user's current tendencies and new things he has learnt .all of these three projects create an excellent source of information to reach the results. their size is more than simple applications, because the time average of each project is considered from one year and it is more for developer. for more information you can visit this site :http//garsia.fdi.ucm.es.Some data on 3 projects come in the tables $1,2,3$.

Table 1. statistical data about the implementation of project p815, p907, ps13, paper [2]

\begin{tabular}{|c|c|c|c|}
\hline Element & P815 & P907 & ps13 \\
\hline Number of classes & 482 & 172 & 130 \\
\hline Number of packages & 45 & 31 & 23 \\
\hline Average methods per class & 5.17 & 4.09 & 5.3 \\
\hline Number of Event & 61 & 10 & 10 \\
\hline Number of rule & 198 & 48 & 39 \\
\hline Number of goal & 135 & 29 & ----- \\
\hline Number of task & 71 & 9 & 39 \\
\hline Number of state machines & 5 & 10 & 8 \\
\hline Sloc logical lines & 15843 & 5393 & 9862 \\
\hline Sloc physical lines & 20009 & 7007 & 13102 \\
\hline
\end{tabular}

Table 2. scale factors applied to the projects,paper[2]

\begin{tabular}{|c|c|c|c|}
\hline Scale factors & P815 & P907 & Ps13 \\
\hline Procedentness & Nominal & High & high \\
\hline Development flexibility & High & High & nominal \\
\hline Architecture/risk resolution & Extra high & Extra high & nominal \\
\hline Team cohesion & High & Very high & Very high \\
\hline Process maturity & Low & nominal & Nominal \\
\hline
\end{tabular}

Table 3. cost factors applied to the projects, paper[2]

\begin{tabular}{|c|c|c|c|}
\hline Cost drivers & P815 & P907 & Ps13 \\
\hline Product reliability and complexity & High & Nominal & Very high \\
\hline reusability & Very high & Very high & Nominal \\
\hline Platform difficulty & High & Very high & High \\
\hline Personnel capability & Nominal & Nominal & Nominal \\
\hline Personnel experience & Low & Nominal & High \\
\hline Facilities & Nominal & High & High \\
\hline Required development schedule & Nominal & nominal & Nominal \\
\hline
\end{tabular}

\section{COCOMO Definition}

Copyright $@ 2015$ MECS
COCOMO principle comes from implicit cost model. the word "implicit" means complexities and ambiguities 
of the model can be understood because of the simplicity of the model. this ability permits us to know exactly why the model evaluates it. In $1981 \mathrm{dr}$ bohem, invented this model for the first time, he had big steps in the evolution process of today software.until today many actions have been done in order to correct and improve software evolution techniques and process application programs and many changes have been done. Science engineers have done many proceedings for limited use of this software, finally they have succeeded in parts : (off-theshelf) become ready to use, packed software(cost),design and management of evolutional process of software, have more advancement,so that today software is reachable as a product for public.

These changes made engineers to correct current model .so, California university as well as software engineering center(use-cse), and organizations which are members of COCOMO 2 project council, decided to present COCOMO 2 model,so they wanted to remove all of its deficiencies and present a non-defective model. today the edited COCOMO (COCOMO2) can be very useful in application software of estimating costs. The evaluation of how much do software projects cost, is done according to their size, human resources, and time.COCOMO2 shows the other parts in different ways:

1 source line codes(sloc):one line of codes refers to the least parts that a programmer can produce. however, there are some elements which are not sloc such as: break line character,explanations or compiler instructions.

2 Unadjusted function points (ufp):they state the amount of agency in a software project and a set of dedicated project factors. they can be used at the beginning of the project,when the source codes are not reachable yet, to determine the desired size for the system.ufp usually is translated to sloc. the base of main COCOMO model [10] is rather development effort(DE).

$\mathrm{DE}=\mathrm{a}^{*}(\operatorname{size})^{\wedge} \mathrm{b}$
Which the size will be counted in the guidance of thousand delivery sources.a and b constants, depend on the mode of projects` development. And also DE is being counted by every individual per month.

$$
\begin{aligned}
& \mathrm{PM}=\mathrm{A}^{*} \operatorname{size}^{\mathrm{E}} \prod_{\mathrm{I}=1}^{17} \mathrm{EMi} \\
& \mathrm{A}=2.94(\text { for COCOMO 2,2000) }
\end{aligned}
$$

$\mathrm{E}=$ scale factor(table 6)

PM is the period of time that a person has devoted to complete the software process during the month. the main COCOMO limits the correctness because it can not handle ironware and personnel .modern tools and their properties are being used to influence on cost projects. Before, Boehm`s goal was COCOMOs average,[10,14]. He multiplied drive cost by an equal to a new variable to increase the correctness of the main COCOMO: EFA (Try to adjust the factor) that is indicated in table 4 .

Table 4. DE for intermediate COCOMO, paper [11]

\begin{tabular}{|c|c|}
\hline Development mode & Intermediate Effort Equation \\
\hline Organic & $\mathrm{DE}=\mathrm{EAF}^{*} 3.2 *(\mathrm{SIZE})^{1.05}$ \\
\hline Semi-detached & $\mathrm{DE}=\mathrm{EAF}^{*} 3.0^{*}(\mathrm{SIZE})^{1.12}$ \\
\hline Embedded & $\mathrm{DE}=\mathrm{EAF}^{*} 2.8^{*}(\mathrm{SIZE})^{1.2}$ \\
\hline
\end{tabular}

The expression "EFA" is the multiplication of 15 costs drives $[12,13]$ that is indicated in table 5 .

For example: If in a project Rely=low, Cplx=extra high Time=very high,STDR=high, rest parameters=nominal, then, $\mathrm{EAF}=0.75 * 1.08 * 1.65 * 1.03 * 1.06 * 1$.

If the value of all 15 drives is normal the value of EAF equals to 1.Generally drive costs divides into four categories $[10,14]$

\section{Product: Rely,DATA,CpLX \\ Platform:TIME,STOR,VIRT,IuRN}

Personnel:ACAP,AEXP,PCAP,VEXP,LEXP

Project:MODD,TOOL,CSED

Table 5. Intermediate COCOMO cost drivers with multipliers[11]

\begin{tabular}{|c|c|c|c|c|c|c|c|}
\hline $\mathrm{n}$ & Cost Driver Symbol & Very low & Low & Nominal & High & Very high & Extra high \\
\hline 1 & RELY & 0.75 & 0.88 & 1 & 1.15 & 1.40 & - \\
\hline 2 & DATA & - & 0.94 & 1 & 1.08 & 1.16 & - \\
\hline 3 & CPLX & 0.70 & 0.85 & 1 & 1.15 & 1.30 & 1.65 \\
\hline 4 & TIME & - & - & 1 & 1.11 & 1.30 & 1.66 \\
\hline 5 & STOR & - & - & 1 & 1.06 & 1.21 & 1.56 \\
\hline 6 & VIRT & - & 0.87 & 1 & 1.15 & 1.30 & - \\
\hline 7 & TURN & - & 0.87 & 1 & 1.07 & 1.15 & - \\
\hline 8 & ACAP & 1.29 & 1.13 & 1 & 0.91 & 0.82 & - \\
\hline 9 & AEXP & 1.42 & 1.17 & 1 & 0.86 & 0.70 & - \\
\hline 10 & PCAP & 1.21 & 1.10 & 1 & 0.90 & - & - \\
\hline 11 & VEXP & 1.14 & 1.07 & 1 & 0.95 & - & - \\
\hline 12 & LEXP & 1.24 & 1.10 & 1 & 0.91 & 0.82 & - \\
\hline 13 & MODP & 1.24 & 1.10 & 1 & 0.91 & 0.83 & - \\
\hline 14 & TOOL & 1.23 & 1.08 & 1 & 1.04 & 1.10 & - \\
\hline 15 & SCED & & & - & - \\
\hline
\end{tabular}


Table 6. Scale Factor Estimation

\begin{tabular}{|c|c|c|c|c|c|c|}
\hline Name & Very low & Low & Nominal & High & Very high & Extra high \\
\hline Precedentedness & $(0.05)$ & $(0.04)$ & $(0.03)$ & $(0.02)$ & $(0.01)$ & $(0.00)$ \\
\hline Flexibility & $(0.05)$ & $(0.04)$ & $(0.03)$ & $(0.02)$ & $(0.01)$ & $(0.00)$ \\
\hline Significant risks eliminated & $(0.05)$ & $(0.04)$ & $(0.03)$ & $(0.02)$ & $(0.01)$ & $(0.00)$ \\
\hline Team interaction process & $(0.05)$ & $(0.04)$ & $(0.03)$ & $(0.02)$ & $(0.01)$ & $(0.00)$ \\
\hline Process maturity & $(0.05)$ & $(0.04)$ & $(0.03)$ & $(0.02)$ & $(0.01)$ & $(0.00)$ \\
\hline
\end{tabular}

\section{MATHEMATICAL MODELS}

\section{A. Fuzzy Element Proposed System}

Soft computing are contained, variant types of fuzzy systems, neural networks, genetic algorithms, etc that Be used in applications effort estimation . Fuzzy theory was developed by Zadeh [4], a new intelligent method offered To solve several problems than the old calculations.

We have considered The event, rule, goal, task, state machines features to aspect oriented effort estimate. event, rule, goal, task, state machines are as inputs to proposed system for aspect oriented software effort estimation . Then these features were fuzzy, in order to determine the exact value of sloc. Finally, the software cost is calculated using COCOMO 2.

The mamdani Fuzzy systems to calculate the exact value for event in sloc Which is named as fuzzy event(FE) is shown(Figure 1).

Input and output variables event in sloc is given in the range 0 to 1 after the change of scale. we consider Three linguistic variables are low, average, high, with triangular membership functions for these variable(Figure 2). Fuzzy rules is presented in Figure3, to determine the exact amount of fuzzy event value by experts working. As an example rules for event element : if event sloc is low then fuzzy event sloc is low, if event sloc is average then fuzzy event sloc is average, if event sloc is high then fuzzy event sloc is high.

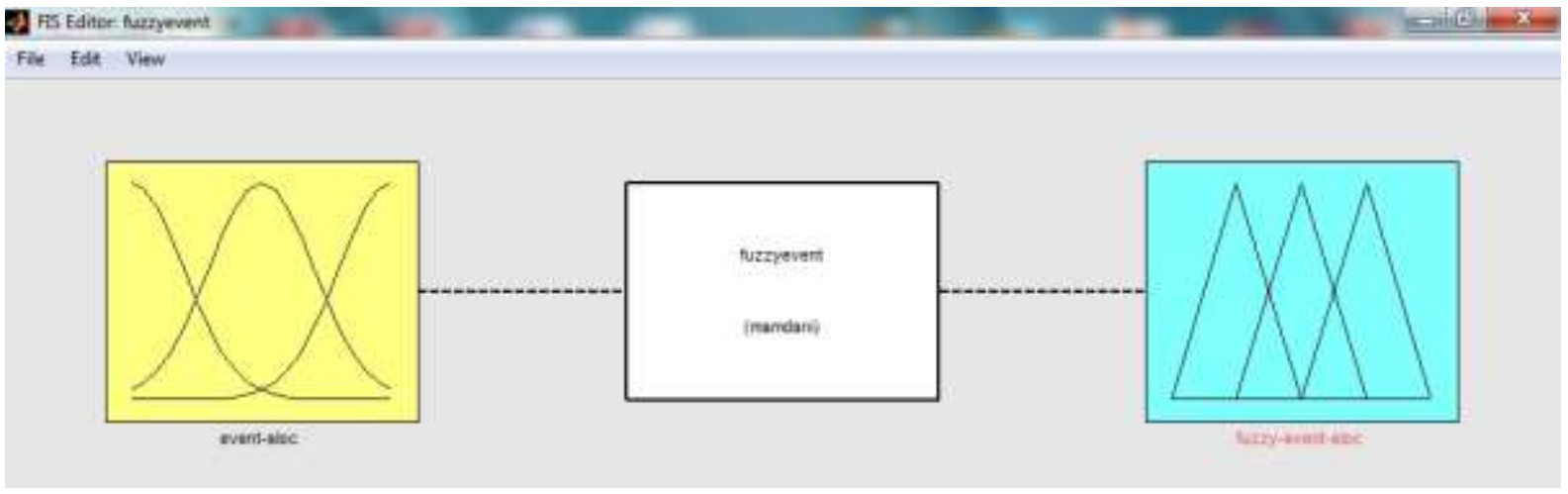

Fig. 1. fuzzy event in sloc

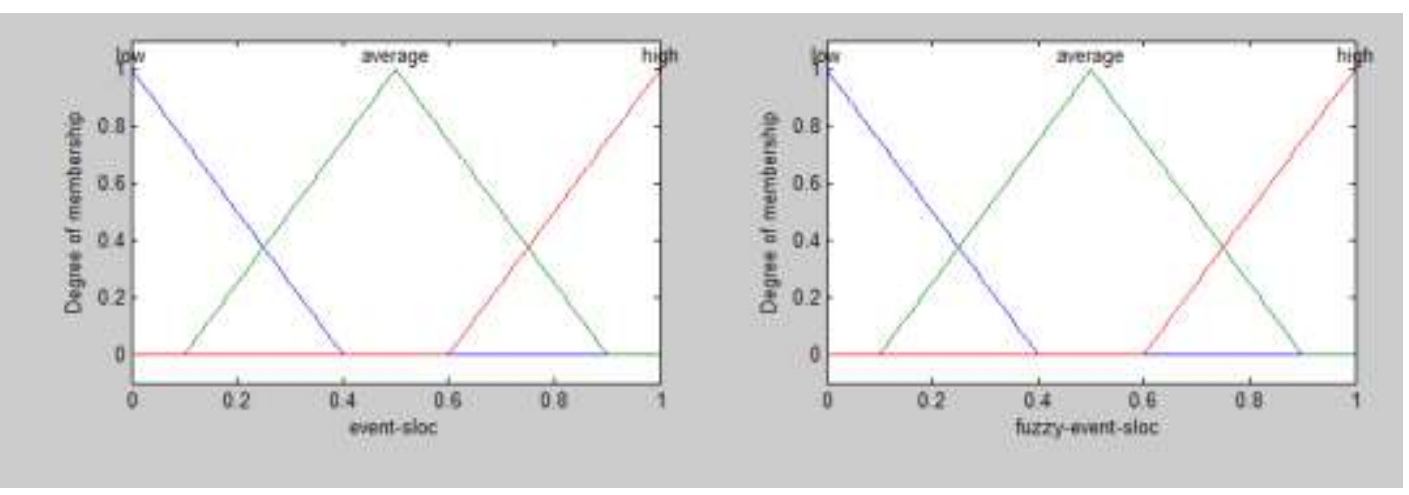

Fig. 2. fuzzy input and output variables for event in sloc

1. If (event-sloc is low) then (fuzzy-event-sloc is average) (1)

2. If (event-sloc is average) then (fuzzy-event-sloc is high) (1) 3. If (event-sloc is high) then (fuzzy-event-sloc is high) (1)

Fig. 3. fuzzy rules for fuzzy event in sloc
Fuzzy modeling so done for other parameters the rule, goal, task, state machines as well. Acquiring fuzzy values for each element, we can create equation 4 and as well as convert the equation 1 to relation 5 . After fuzzifying lements in sloc, Must be calculated the average value of each element per item. Gaining a new fuzzy total sloc for 
each project to wit total pure fuzzy sloc and total weighted fuzzy sloc, are calculated the effort of projects using COCOMO2 method by placement in equation 3 .

Total Pure Fuzzy Sloc $=$ FE + FR + FG + FT + FS

Where FE is fuzzy actual event and FR is fuzzy actual rule and FG is fuzzy actual goal and FT is fuzzy actual task and FS is fuzzy actual state machines in sloc for 3 projects .

Total Weighted Fuzzy Sloc $=\mathrm{FA}_{\mathrm{E}} *(\# \mathrm{E})+\mathrm{FA}_{\mathrm{R}} *$ $(\# \mathrm{R})+\mathrm{FA}_{\mathrm{G}} *(\# \mathrm{G})+\mathrm{FA}_{\mathrm{T}} *(\# \mathrm{~T})+\mathrm{FA}_{\mathrm{S}} *(\# \mathrm{~S})$
Where $F A_{E}$ is fuzzy average event and $F A_{R}$ is fuzzy average rule and $F A_{G}$ is fuzzy average goal and $F A_{T}$ is fuzzy average task and $\mathrm{FA}_{\mathrm{S}}$ is fuzzy average state machines in sloc for 3 projects .

In addition to fuzzifying the elements in sloc,number of elements fuzzify To improve the results and we got new relationship 6 from 5. Figure 4,5 is presented membership functions and fuzzy rules for fuzzifying number of element after change scale to range $0-1$.

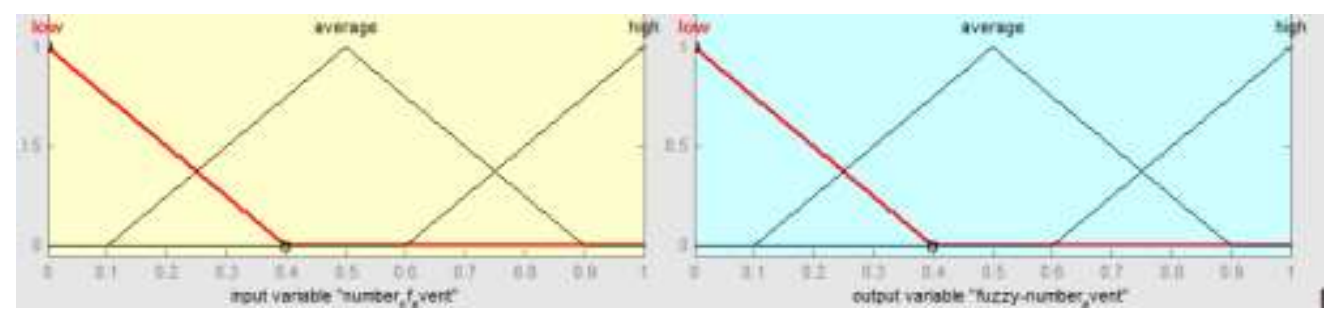

Fig. 4. fuzzy input and output variables for number of event

1. If (number, of event is low) then (fuzzy-number, event is average) (1)

2. If (number_of_event is average) then (fuzzy-number_event is high) (1)

3. If (number_of_event is high) then (fuzzy-number_event is high) (1)

Fig. 5. fuzzy rules for fuzzy number of event

Total Weighted Fuzzy Sloc with fuzzy element $=$ $\mathrm{FA}_{\mathrm{E}} *(\# \mathrm{FE})+\mathrm{FA}_{\mathrm{R}} *(\# \mathrm{FR})+\mathrm{FA}_{\mathrm{G}} *(\# \mathrm{FG})+\mathrm{FA}_{\mathrm{T}} *$ $(\# \mathrm{FT})+\mathrm{FA}_{\mathrm{S}} *(\# \mathrm{FS})$

In equation $6, \mathrm{FA}_{\mathrm{E}}$ is fuzzy average event per fuzzy Item and $F A_{R}$ is fuzzy average rule per fuzzy Item and $F_{G}$ is fuzzy average goal per fuzzy Item and $F A_{T}$ is fuzzy average task per fuzzy Item and $F A_{S}$ is fuzzy average state machines per fuzzy Item in sloc for 3 projects, \#FE is fuzzy number of events and \#FR is fuzzy number of rules and \#FG is fuzzy number of goals and \#FT is fuzzy number of tasks and \#FS is fuzzy number of state machines.

We used geometric mean and Harmonic mean instead of the arithmetic mean for average fuzzy element per fuzzy item,Further research to investigate more deeply. We obtained the equations 9 and 10 Using equations 7 and 8 , in which $\mathrm{G}_{\mathrm{i}}, \mathrm{H}_{\mathrm{i}}$ are geometric meen and harmonic meen sloc per element .

geometric meen $\sqrt[n]{x_{1} \cdot x_{2} \cdots \cdots \cdot x_{n}}$

$$
\text { harmonic meen }=\frac{n}{\frac{1}{x_{1}}+\frac{1}{x_{2}}+\cdots+\frac{1}{x_{n}}}
$$

Total geometric Fuzzy Sloc with fuzzy elem $=\mathrm{FG}_{\mathrm{E}} *$ $(\# \mathrm{FE})+\mathrm{FG}_{\mathrm{R}} *(\# \mathrm{FR})+\mathrm{FG}_{\mathrm{G}} *(\# \mathrm{FG})+\mathrm{FG}_{\mathrm{T}} *(\# \mathrm{FT})+$ $\mathrm{FG}_{\mathrm{S}} *$ (\#FS)

Total harmonic Fuzzy Sloc with fuzzy element $=$ $\mathrm{FH}_{\mathrm{E}} *(\# \mathrm{FE})+\mathrm{FH}_{\mathrm{R}} *(\# \mathrm{FR})+\mathrm{FH}_{\mathrm{G}} *(\# \mathrm{FG})+\mathrm{FH}_{\mathrm{T}} *$ $(\# \mathrm{FT})+\mathrm{FH}_{\mathrm{S}} *(\# \mathrm{FS})$

\section{B. Fuzzy Combinatorial Proposed System of Density Elements}

In the last section we were considered the variables into separate factors. Then we have created for each individual fuzzy rules. But in this part We proposed the following system (figure 6) and created the fuzzy rules after fuzzifying event sloc per number of event(eventdensity), rule sloc per number of rule(rule-density), goal sloc per number of goal(goal-density), task sloc per number of task(task-density), state machines sloc per number of state machines(satate machines density) features combination of these factors(figure 7).

Input and output variables in sloc per item Were scaled change to 0 - 1 . we bring up Three linguistic variables are low, average, high, with triangular membership functions for these variable(Figure 8). Finally, the software cost is calculated using COCOMO 2.

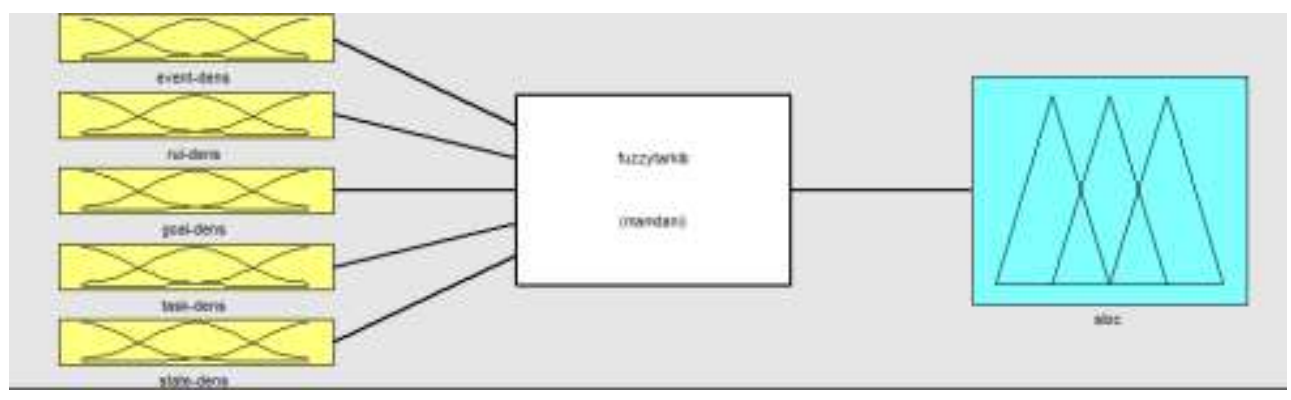

Fig. 6. fuzzy proposed system for elements density in sloc 
1. If (event-dens is low) and (rul-dens is low) and (goal-dens is average) and (task-dens is low) and (state-dens is low) then (sloc is average) (1) 2. If (event-dens is average) and (rul-dens is average) and (goal-dens is low) and (task-dens is high) and (state-dens is average) then (sloc is low) (1) 3. If (event-dens is high) and (rul-dens is high) and (task-dens is low) and (state-dens is high) then (sloc is high) (1)

Fig. 7. fuzzy rules for proposed system with for elements density

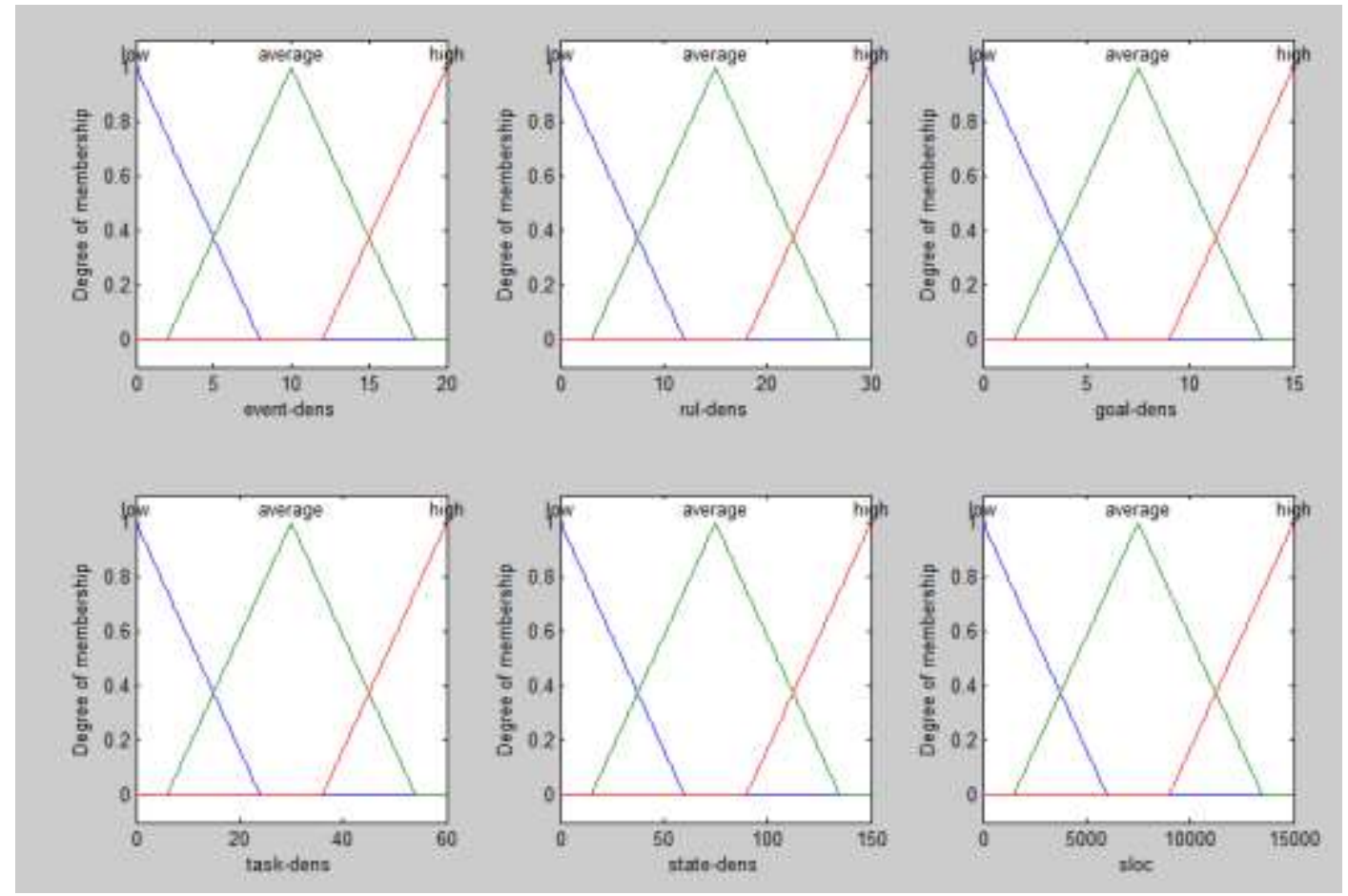

Fig. 8. fuzzy membership function for proposed system with elements density

\section{EXPERIMENTAL RESULTS}

We implement our proposed system in MATLAB version 7.12 on Laptop, 1.7 GHZ CPU. Then the exact value of elements are calculated after scaled to range from 0 to 1 Dividing the value of each element, for each project, by the largest amount of that element in projects(table 7).As shown in Figure 11 when the event p815 =1 the Fuzzy event, 0.87 respectively and for p907 when event $=0.194$ the fuzzy event Obtained 0.545 (figure 12).also in PSI 3 when event $=0.388$ the fuzzy event Obtained 0.824(figure 13). To avoid repetition, the following calculation is explains only one element of the project. Considering the figure 14, for p907 when rule $=0.433$ the fuzzy rule Obtained 0.866 . fuzzy goal Was calculated 0.5 in p907(figure 15). For the task element in p907 Was computed when task $=0.655$, fuzzy task $=0.855$ (figure 16).Finally, each of state machines for p907 $=0.659$ Obtained fuzzy state machines $=0.854$ (figure 17).

Table 7. elements Been scaled to the range 0 to 1 .

\begin{tabular}{|c|c|c|c|}
\hline Element & P815 & P907 & Ps13 \\
\hline Event & 1 & 0.194 & 0.388 \\
\hline Rule & 1 & 0.433 & 0.491 \\
\hline Goal & 1 & 0.069 & \\
\hline Task & 1 & 0.655 & 0.382 \\
\hline State machines & 0.135 & 0.659 & 1 \\
\hline
\end{tabular}

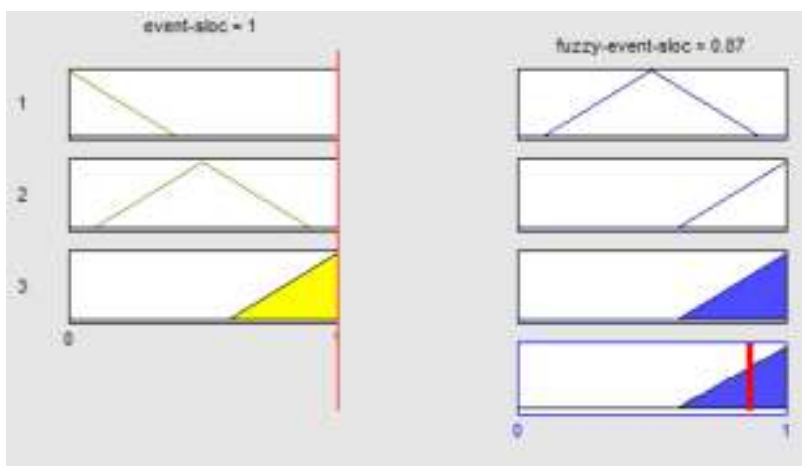

Fig. 11. The exact amount for p815 fuzzy event

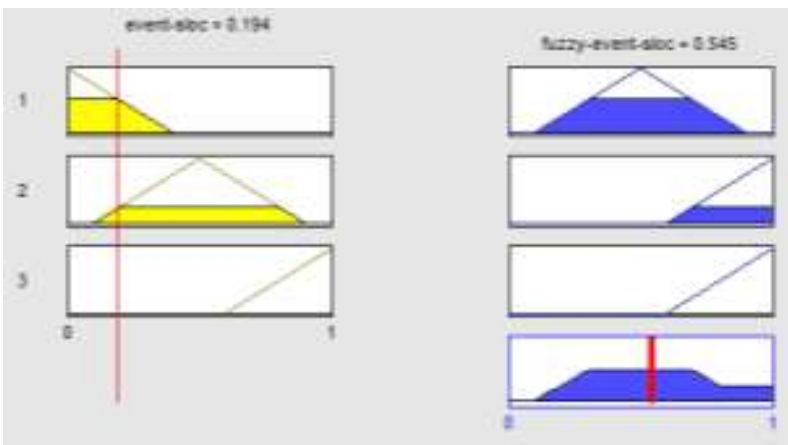

Fig. 12. The exact amount for p907 fuzzy event 


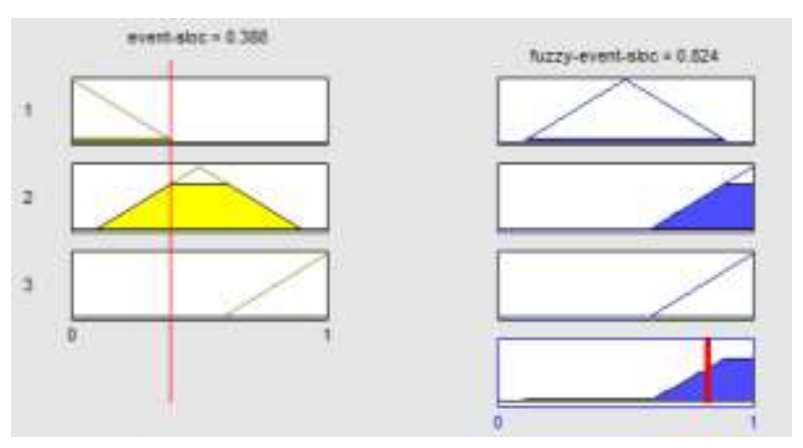

Fig. 13. The exact amount for PSI3 fuzzy event

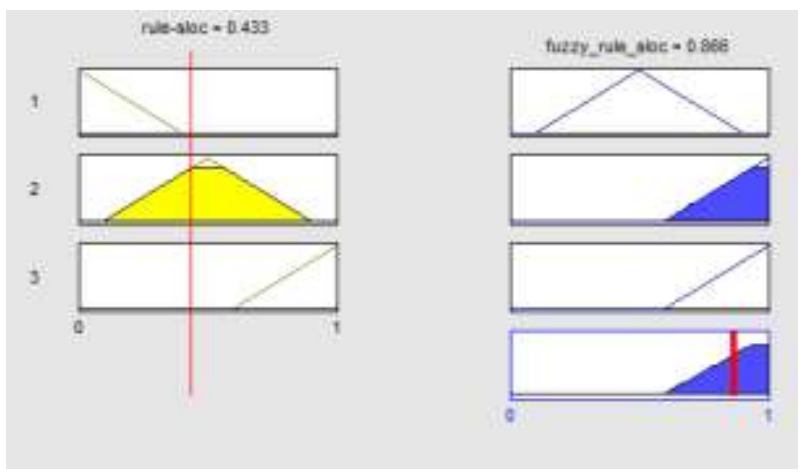

Fig. 14. The exact amount for p907 fuzzy rule

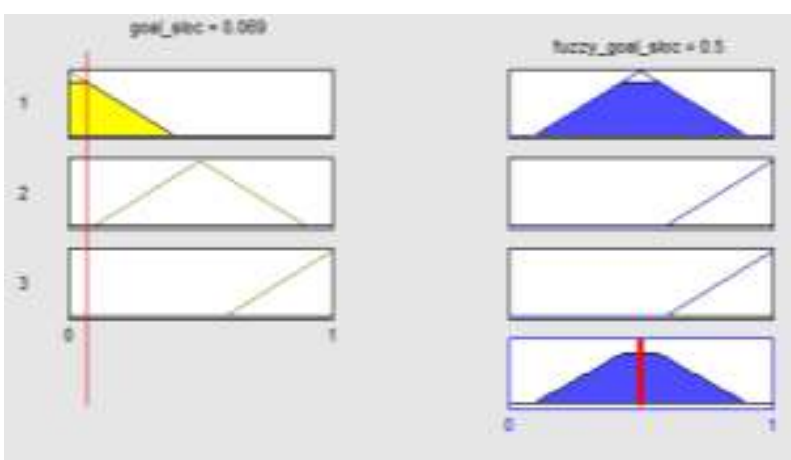

Fig. 15. The exact amount for p907 fuzzy goal

The scaled Fuzzy elements are Obtained in Table 8.The actual amount Fuzzy elements are calculated after scaled Multiplying the value of each fuzzy scale element, for each project, by the largest amount of that element in projects from table 1 (show table 9 ).
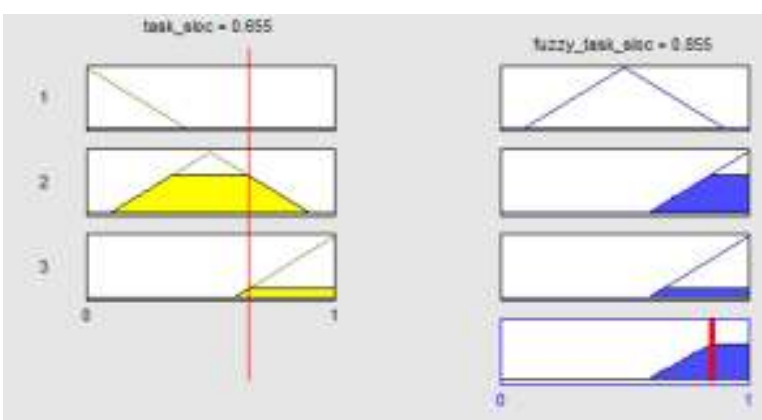

Fig. 16. The exact amount for p907 fuzzy task

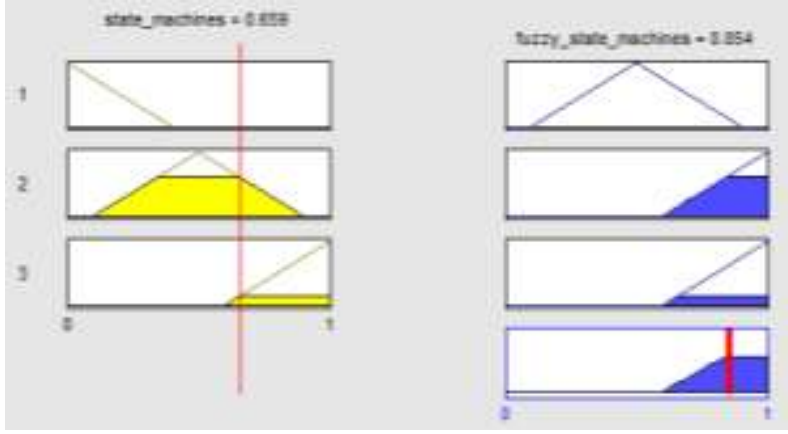

Fig. 17. The exact amount for p907 fuzzy state machines

Table 8. results for scaled fuzzy element into sloc.

\begin{tabular}{|c|c|c|c|}
\hline element & P815 & P907 & Ps13 \\
\hline Scales Fuzzy Event & 0.87 & 0.545 & 0.824 \\
\hline Scales fuzzy Rule & 0.87 & 0.866 & 0.87 \\
\hline Scales fuzzy Goal & 0.87 & 0.5 & \\
\hline Scales fuzzy Task & 0.87 & 0.855 & 0.806 \\
\hline Scales fuzzy State machines & 0.513 & 0.854 & 0.87 \\
\hline
\end{tabular}

We then calculate the fuzzy average sloc per items with fuzzy actual elements, To apply Equation 4,5,6,9,10 and obtain a new value for the total fuzzy sloc to calculate new value for the cost of software using COCOMO 2. The comparison sloc is given in the table 10 for 3 projects, Column c,d,e,f,g,h were obtained from Equation 1,4,5,6,9,10 respectively.

In proposed system fuzzy combinatorial density elements for project p907 When event-density $=8.6$ and rule-density $=19.2$ and goal-density $=3.79$ and taskdensity $=57.8$ and state machines density $=69.1 \mathrm{sloc}=2450$ Obtained(figure 18).

Then we have used usc COCOMO 2 program In order to compute effort [17](figure 19-22). effort was calculated 29.3PM,10.1 months for Project p907 using the traditional method (figure 19) Whereas Obtained 6.6 PM,6.5 months with total weighted sloc from equation 1 respectively(figure 20). But as noted in the figure 21, we find that effort Obtained 7.3 PM,6.7 months the with fuzzy combinatorial proposed system of elements density. The effort Was calculated 44.8 PM,12 months for PSI3 with fuzzy combinatorial proposed system of elements density that result was much better than previous methods(figure 22).

Comparison the effort obtained by usc COCOMO 2 tool Are given in the table 11. Difference between the projected cost to the actual cost is obtained in table 12 . According to the data in Table 12, for p907 project Minimum Deviation from the real cost is 0.6 with Total weighted sloc approach and p815 project Minimum Deviation is 0.3 with Harmonic mean for fuzzy sloc per item, Finally PSI3 project Minimum Deviation from the real cost is 24.2 with fuzzy combinatorial proposed system of elements density. 
Table 9. results for actual fuzzy element into sloc.

\begin{tabular}{|c|c|c|c|c|}
\hline element & P815 & P907 & Ps13 & Average sloc per item \\
\hline Actual Fuzzy Event & 385.41 & 241.435 & 365.03 & 22.32 \\
\hline Actual Fuzzy Rule & 1853.1 & 1844.58 & 1853.1 & 31.76 \\
\hline Actual Fuzzy Goal & 1375.47 & 790.5 & 0 & 18.72 \\
\hline Actual Fuzzy Task & 689.91 & 678.015 & 639.15 & 33.81 \\
\hline Actual Fuzzy State machines & 537.624 & 894.992 & 911.76 & 103.66 \\
\hline Total Sloc & 4841.514 & 2393.23 & 3769.05 & \\
\hline
\end{tabular}

In this study, The Magnitude of Relative Error (MRE) will be used, Among the available indicators, in order to compare models and cost estimates. MRE for each observation i can be obtained as:

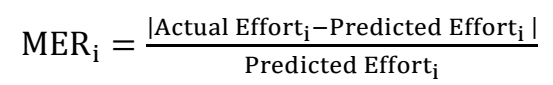

Mean Magnitude of Relative Error (MMRE) can be achieved through the summation of MRE over $\mathrm{N}$ observations:
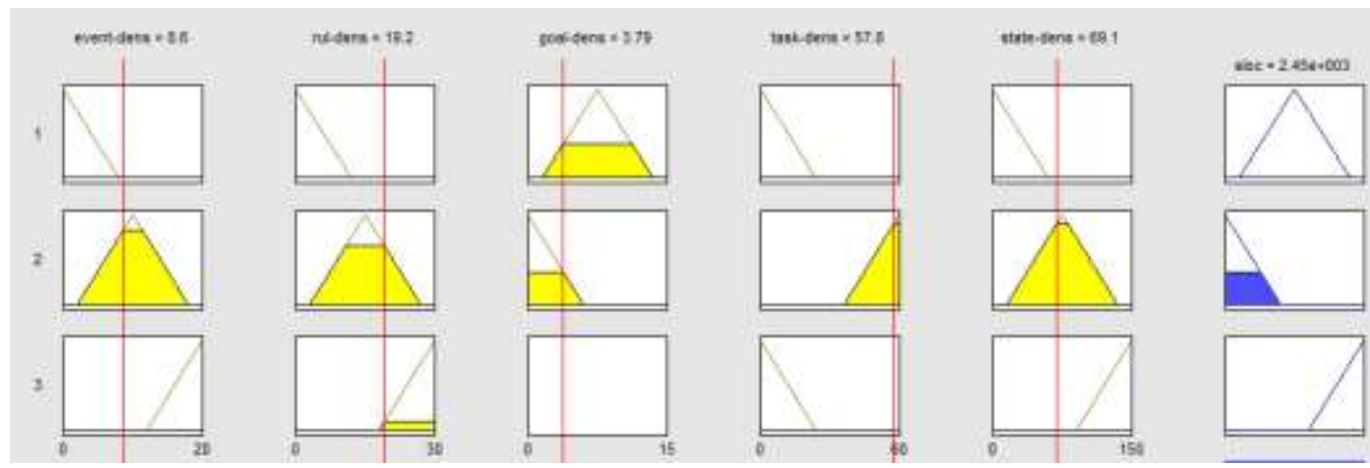

Fig. 18. The exact amount for p907 fuzzy combinatorial proposed system of elements density

Table 10. Comparison the SLoc obtained for projects

\begin{tabular}{|c|c|c|c|c|c|c|c|c|c|}
\hline $\mathrm{P} \#$ & traditional(A) & $\begin{array}{l}\text { Total sloc } \\
\text { agent } \\
\text { element(B) }\end{array}$ & $\begin{array}{c}\text { Total } \\
\text { weighted } \\
\text { sloc }(C)\end{array}$ & $\begin{array}{l}\text { Total pure } \\
\text { fuzzy agent } \\
\text { sloc(D) }\end{array}$ & $\begin{array}{c}\text { Total } \\
\text { weighted } \\
\text { fuzzy } \\
\text { sloc }(\mathrm{E})\end{array}$ & $\begin{array}{c}\text { Total } \\
\text { weighted } \\
\text { fuzzy sloc } \\
* \text { fuzzy } \\
\text { element }(\mathrm{F})\end{array}$ & $\begin{array}{l}\text { Geometric } \\
\text { mean } \\
\text { For fuzzy } \\
\text { sloc per } \\
\text { item }(\mathrm{G}) \\
\end{array}$ & $\begin{array}{l}\text { Harmonic } \\
\text { mean for } \\
\text { fuzzy sloc } \\
\text { per } \\
\text { item }(\mathrm{H}) \\
\end{array}$ & $\begin{array}{c}\text { fuzzy } \\
\text { combinatorial } \\
\text { proposed system } \\
\text { of elements } \\
\text { density(I) }\end{array}$ \\
\hline P907 & 5393 & 2330 & 2236 & 4449 & 3632 & 4071 & 3990 & 3908 & 2450 \\
\hline P815 & 15843 & 5089 & 7666 & 4841 & 13098 & 5916 & 5802 & 5687 & 7500 \\
\hline PS13 & 9862 & 2570 & 2455 & 3769 & 3610 & 3769 & 3369 & 3280 & 12900 \\
\hline
\end{tabular}

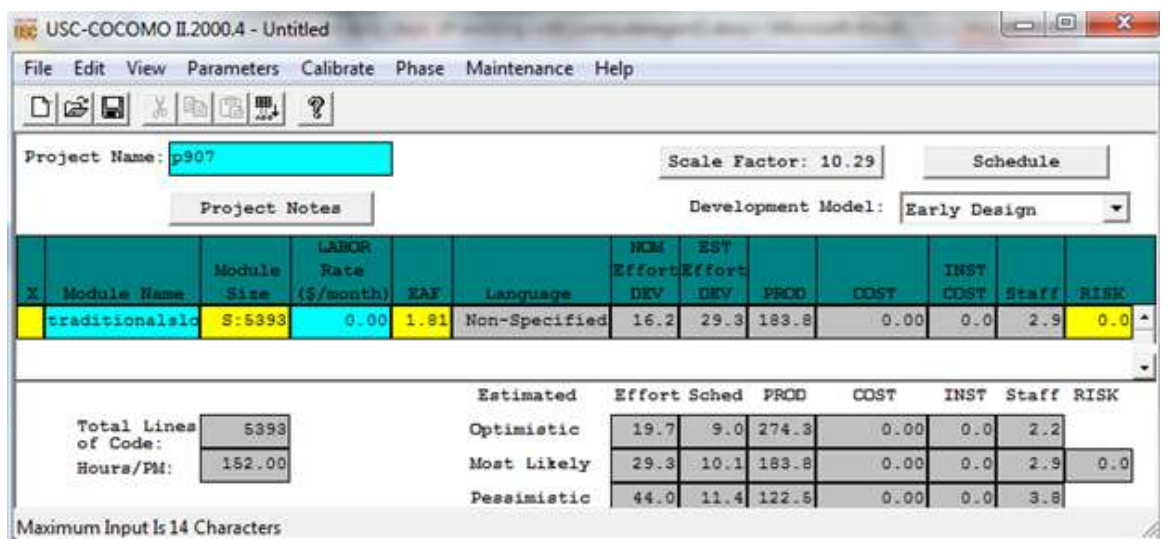

Fig. 19. The effort for $\mathrm{p} 907$ with traditional sloc 


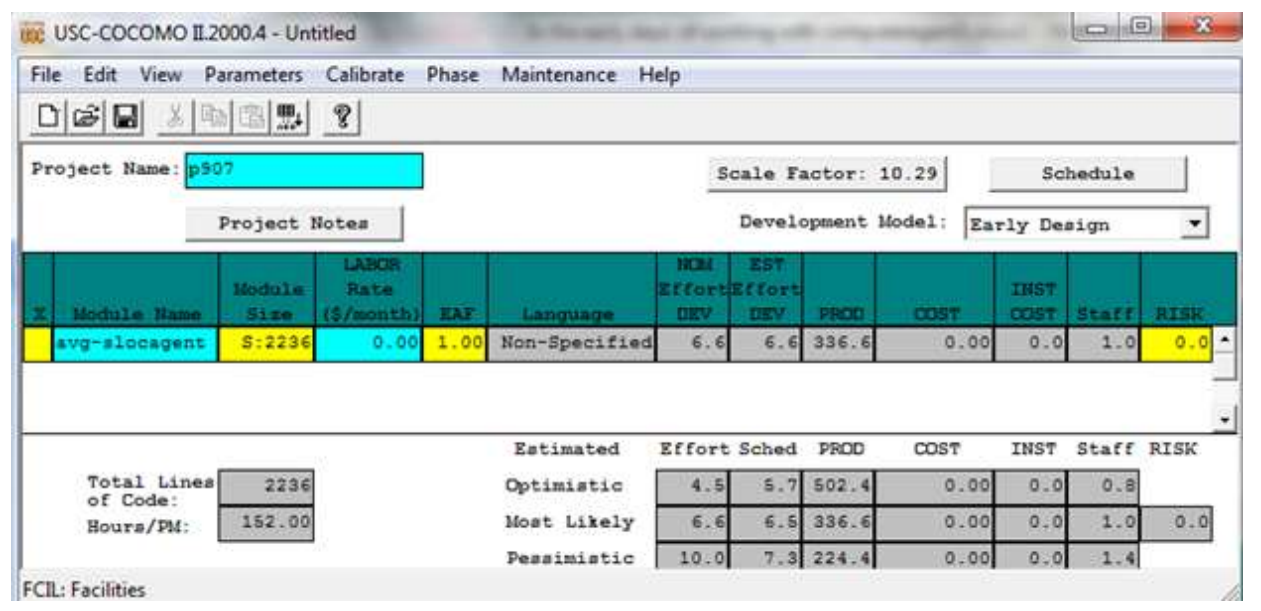

Fig. 20. The effort for p907 with total weighted sloc from equation 1

Table 11. comparison the effort obtained by usc COCOMO 2 tool.

\begin{tabular}{|c|c|c|c|c|c|c|c|c|c|c|}
\hline Project & $\begin{array}{l}\text { Real } \\
\text { cost }\end{array}$ & $\begin{array}{l}\text { Traditional } \\
\text { (A) }\end{array}$ & $\begin{array}{l}\text { Total } \\
\text { sloc agent } \\
\text { element } \\
\text { (B) }\end{array}$ & $\begin{array}{c}\text { Total } \\
\text { weighted } \\
\text { sloc }(\mathrm{C})\end{array}$ & $\begin{array}{l}\text { Total pure } \\
\text { fuzzy } \\
\text { agent } \\
\text { sloc(D) }\end{array}$ & $\begin{array}{c}\text { Total } \\
\text { weighted } \\
\text { fuzzy } \\
\text { sloc }(E)\end{array}$ & $\begin{array}{c}\text { Total } \\
\text { weighted } \\
\text { fuzzy sloc } \\
\text { *fuzzy } \\
\text { element (f) }\end{array}$ & $\begin{array}{l}\text { Geometri } \\
\text { c mean } \\
\text { For fuzzy } \\
\text { sloc per } \\
\text { item }(G)\end{array}$ & $\begin{array}{l}\text { Harmonic } \\
\text { mean for } \\
\text { fuzzy sloc } \\
\text { per item }(H)\end{array}$ & $\begin{array}{c}\text { Fuzzy } \\
\text { combinatorial } \\
\text { proposed } \\
\text { system of } \\
\text { elements } \\
\text { density(I) }\end{array}$ \\
\hline P907 & $\begin{array}{c}6 \mathrm{PM}, \\
5 \text { months }\end{array}$ & $\begin{array}{c}\text { 29.3PM, } \\
\text { 10.1months }\end{array}$ & $\begin{array}{c}6.9 \mathrm{PM}, \\
6.6 \text { months }\end{array}$ & $\begin{array}{c}6.6 \mathrm{PM}, \\
6.5 \mathrm{months}\end{array}$ & $\begin{array}{l}\text { 13.3 PM, } \\
\text { 8months }\end{array}$ & $\begin{array}{c}\text { 10.9PM, } \\
\text { 7.5months }\end{array}$ & $\begin{array}{l}\text { 12.2 PM, } \\
\text { 7.8months }\end{array}$ & $\begin{array}{l}\text { 11.9 PM, } \\
\text { 7.7months }\end{array}$ & $\begin{array}{l}\text { 11.7 PM, } \\
\text { 7.7months }\end{array}$ & $\begin{array}{c}\text { 7.3 PM, } \\
6.7 \text { months }\end{array}$ \\
\hline P815 & $\begin{array}{c}18 \mathrm{PM}, \\
9 \text { months }\end{array}$ & $\begin{array}{l}\text { 118.8PM, } \\
\text { 16months }\end{array}$ & $\begin{array}{l}\text { 16.3PM, } \\
8.7 \text { months }\end{array}$ & $\begin{array}{l}25 \text { PM, } \\
9.9 \text { months }\end{array}$ & $\begin{array}{l}\text { 15.4PM, } \\
8.5 \text { months }\end{array}$ & $\begin{array}{c}\text { 44PM, } \\
11.8 \text { months }\end{array}$ & $\begin{array}{l}\text { 19.1 PM, } \\
\text { 9.1months }\end{array}$ & $\begin{array}{l}\text { 18.7 PM, } \\
9.1 \text { months }\end{array}$ & $\begin{array}{l}\text { 18.3 PM, } \\
\text { 9months }\end{array}$ & $\begin{array}{l}24.5 \text { PM, } \\
9.8 \text { months }\end{array}$ \\
\hline PS13 & $\begin{array}{c}\text { 69PM, } \\
18 \text { months }\end{array}$ & $\begin{array}{c}\text { 62.8PM, } \\
\text { 13.3months }\end{array}$ & $\begin{array}{c}\text { 8PM, } \\
\text { 7months }\end{array}$ & $\begin{array}{l}\text { 7.7 PM, } \\
6.9 \text { months }\end{array}$ & $\begin{array}{l}\text { 12.1 PM, } \\
\text { 8months }\end{array}$ & $\begin{array}{l}\text { 11.5 PM, } \\
\text { 7.9months }\end{array}$ & $\begin{array}{c}11 \mathrm{PM}, \\
7.7 \mathrm{months}\end{array}$ & $\begin{array}{l}\text { 10.7 PM, } \\
7.7 \text { months }\end{array}$ & $\begin{array}{l}10.4 \mathrm{PM}, \\
7.6 \text { months }\end{array}$ & $\begin{array}{l}\text { 44.8 PM, } \\
\text { 12months }\end{array}$ \\
\hline
\end{tabular}

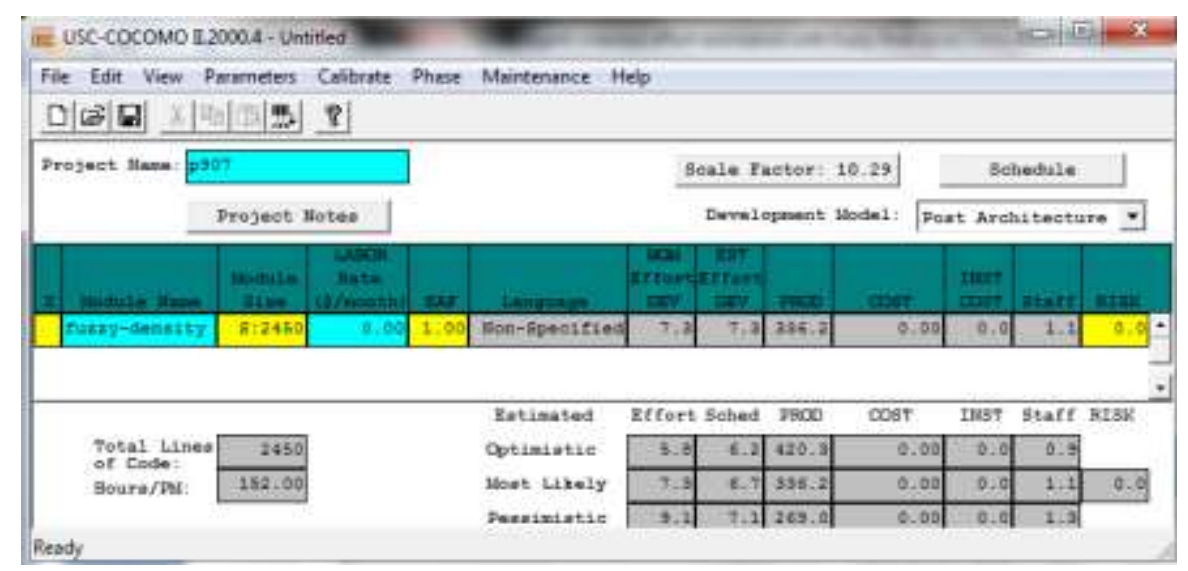

Fig. 21. The effort for p907 with fuzzy combinatorial proposed system of elements density

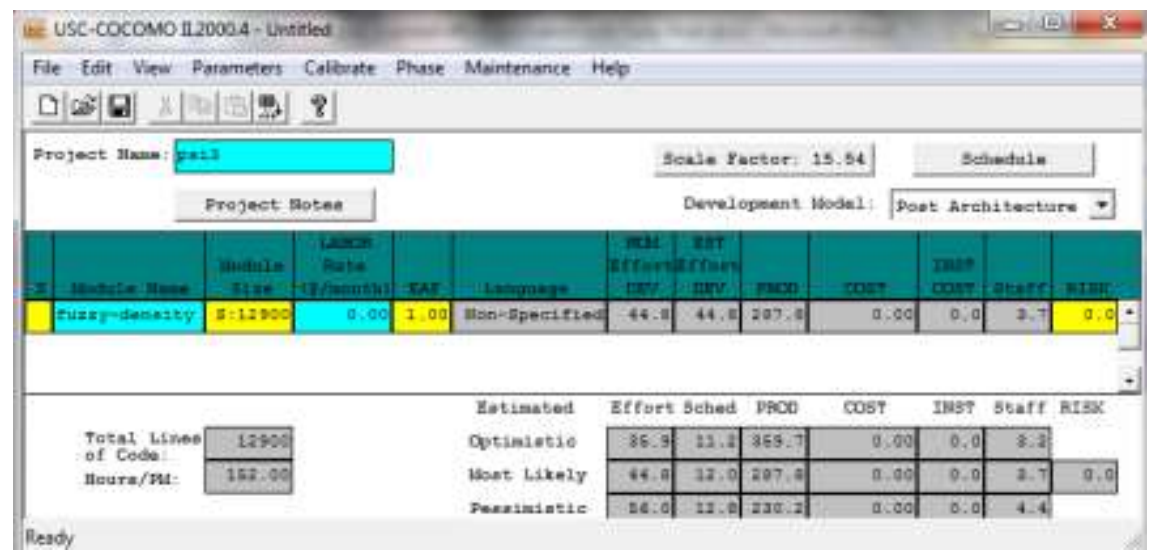

Fig. 22. The effort for PSI3 with fuzzy combinatorial proposed system of elements density 


\section{CONCLUSION}

Our purpose in this research is prediction the exact amount of agent oriented software effort and creating an algorithm for this purpose, as yet,many mentioned algorithms are offered in literature review,and we suggested some methods also.The event, rule, goal, task, state machines features were considered In order to The agent-oriented software cost estimation .To use this feature Was caused agent oriented software size estimates more accurate than the real value.

the new values size obtained By applying different methods based on these features namely Total sloc agent element,Total weighted sloc,Total pure fuzzy agent sloc, Total weighted fuzzy sloc, Total weighted fuzzy sloc *fuzzy element,Geometric mean For fuzzy sloc per item,Harmonic mean for fuzzy sloc per item,fuzzy combinatorial proposed system of elements
density.Finally, was calculated COCOMO2 amount of effort using each method.

between these methods in" fuzzy combinatorial proposed system of elements density" offered algorithm, the amount of Mean Magnitude of Relative Error (MMRE) indicator is lesser than the existing proposed algorithms and the performed calculations in experimental results in table 13,prove this claim .in order to perform future works, the proposed algorithm for agent oriented software's can be developed with Raising The data relating to projects, and also Neural methods can be used in order to determine the exact amount of effort in industrial environments. Probably to be achieved better results By changing the number of linguistic variables, the type of membership function, the number of fuzzy rules as well as changes in the factors considered for the agent oriented software.

Table 12. comparison the Deviation from the real cost

\begin{tabular}{|c|c|c|c|c|c|c|c|c|c|c|}
\hline prj & real & $\begin{array}{c}\text { Tradi- } \\
\text { tional-A }\end{array}$ & $\begin{array}{c}\text { Total sloc } \\
\text { agent } \\
\text { element-B }\end{array}$ & $\begin{array}{c}\text { Total } \\
\text { weighted } \\
\text { sloc (C) }\end{array}$ & $\begin{array}{c}\text { Total } \\
\text { pure } \\
\text { fuzzy } \\
\text { agent } \\
\text { sloc(D) }\end{array}$ & $\begin{array}{c}\text { Total } \\
\text { weighted } \\
\text { fuzzy } \\
\text { sloc (E) }\end{array}$ & $\begin{array}{c}\text { Total } \\
\text { weighted } \\
\text { fuzzy } \\
\text { sloc } \\
* \text { fuzzy } \\
\text { element (f) }\end{array}$ & $\begin{array}{c}\text { Geometric } \\
\text { mean } \\
\text { For fuzzy } \\
\text { sloc per } \\
\text { item(G) }\end{array}$ & $\begin{array}{c}\text { Harmonic } \\
\text { mean for } \\
\text { fuzzy } \\
\text { sloc per } \\
\text { item(H) } \\
\text { combinatorial } \\
\text { proposed } \\
\text { system of } \\
\text { elements } \\
\text { density(I) }\end{array}$ \\
\hline P907 & 6 & 23.3 & 0.9 & 0.6 & 7.3 & 4.9 & 6.2 & 5.9 & 5.7 \\
\hline P815 & 18 & 100.8 & 1.7 & 7 & 2.6 & 26 & 1.1 & 0.7 & 0.3 \\
\hline PS13 & 69 & 6.2 & 61 & 61.3 & 56.9 & 57.5 & 58 & 58.3 & 58.6 & 6.3 \\
\hline sum & & 130.3 & 63.6 & 68.9 & 66.8 & 88.4 & 65.3 & 64.9 & 64.6 \\
\hline
\end{tabular}

Table 13. comparison the mmre

\begin{tabular}{|c|c|c|c|c|c|c|c|c|c|}
\hline Project & $\begin{array}{l}\text { Traditional } \\
\text { (A) }\end{array}$ & $\begin{array}{l}\text { Total sloc } \\
\text { agent } \\
\text { element(B) }\end{array}$ & $\begin{array}{c}\text { Total } \\
\text { weighted } \\
\text { sloc }(\mathrm{C})\end{array}$ & $\begin{array}{l}\text { Total } \\
\text { pure } \\
\text { fuzzy } \\
\text { agent } \\
\text { sloc(D) }\end{array}$ & $\begin{array}{l}\text { Total } \\
\text { weighted } \\
\text { fuzzy } \\
\text { sloc }(E)\end{array}$ & $\begin{array}{c}\text { Total } \\
\text { weighted } \\
\text { fuzzy } \\
\text { sloc } \\
* \text { fuzzy } \\
\text { element (f) }\end{array}$ & $\begin{array}{c}\text { Geometric } \\
\text { mean } \\
\text { For fuzzy } \\
\text { sloc per } \\
\text { item(G) }\end{array}$ & $\begin{array}{l}\text { Harmonic } \\
\text { mean for } \\
\text { fuzzy } \\
\text { sloc per } \\
\text { item }(\mathrm{H})\end{array}$ & $\begin{array}{c}\text { fuzzy } \\
\text { combinatorial } \\
\text { proposed } \\
\text { system of } \\
\text { elements } \\
\text { density(I) }\end{array}$ \\
\hline P907 & 23.3 & 0.130435 & 0.090909 & 0.548872 & 0.449541 & 0.508197 & 0.495798 & 0.487179 & 0.17808 \\
\hline P815 & 100.8 & 0.104294 & 0.28 & 0.168831 & 0.590909 & 0.057592 & 0.037433 & 0.016393 & 0.265306 \\
\hline PS13 & 6.2 & 7.625 & 7.961039 & 4.702479 & 5 & 5.272727 & 5.448598 & 5.634615 & 0.540179 \\
\hline MMRE & 43.43 & 2.61991 & 2.777316 & 1.806728 & 2.013483 & 1.946172 & 1.993943 & 2.046063 & 0.32786 \\
\hline
\end{tabular}

\section{REFERENCES}

[1] Gómez-Sanz, Jorge J., Juan Pavón, and Francisco Garijo. "Estimating costs for agent oriented software." AgentOriented Software Engineering VI. Springer Berlin Heidelberg, 2006. 218-230.

[2] Mahar, Sapna, and Pradeep Kumar Bhatia. "Comparative Analysis of Cost Estimation for Agent Oriented Software \& Traditional Software."

[3] Wang, L-X., "A course in fuzzy systems, and control “,prentice Hall, August 1996.

[4] LA Zadeh; Fuzzy sets. Information and Control (1965), pp. 338-353.

[5] Merlo-Schett, Nancy, Martin Glinz, and Arun Mukhija. "Seminar on Software Cost Estimation WS 2002/2003."

[6] Kamal, Shahid, and Jamal Abdul Nasir. "A Fuzzy Logic Based Software Cost Estimation Model." International
Journal of Software Engineering \& Its Applications 7.2 (2013).

[7] Al Yahya, Majed, Rodina Ahmad, and Sai Lee. "Impact of CMMI Based Software Process Maturity on COCOMO II's Effort Estimation." Int. Arab J. Inf. Technol. 7.2 (2010): 129-137.

[8] Iraji, Mohammad Saber, and Homayun Motameni. "Object Oriented Software Effort Estimate with Adaptive Neuro Fuzzy use Case Size Point (ANFUSP)." International Journal of Intelligent Systems and Applications (IJISA) 4.6 (2012): 14

[9] Milicic, Darko. "Applying COCOMO II." Master's thesis, Blekinge Institute of Technology, Ronneby, Sweden (2004).

[10] BW Bohem. "Software Engineering Economics". Englewood Cliffs, NJ Prentice-Hall, Inc., 1981

[11] Prasad Reddy PVGD,Sudha KR,Rama Sree P, Application of Fuzzy Logic Approach to Software Effort 
Estimation,International Journal of Advanced Computer Science and Applications, 2,5(2011).

[12] Xu, Zhiwei, and Taghi M. Khoshgoftaar. "Identification of fuzzy models of software cost estimation." Fuzzy Sets and Systems 145.1 (2004): 141-163.

[13] Seth, Kirti, Arun Sharma, and Ashish Seth. "Component Selection Efforts Estimation-a Fuzzy Logic Based Approach." International Journal of Computer Science and Security,(IJCSS) 3.3 (2009): 210-215.

[14] Idri, Ali, Alain Abran, and Laila Kjiri. "COCOMO cost model using fuzzy logic." 7th International Conference on Fuzzy Theory \& Techniques. Vol. 27. 2000.

[15] Musílek, Petr, et al. "Software cost estimation with fuzzy models." ACM SIGAPP Applied Computing Review 8.2 (2000): 24-29.

[16] Boehm, Barry W., Ray Madachy, and Bert Steece. Software Cost Estimation with Cocomo II with Cdrom. Prentice Hall PTR, 2000.

[17] use COCOMO 2 application . http://sunset.usc.edu/ available_tools/index.htm

\section{Author Profile}

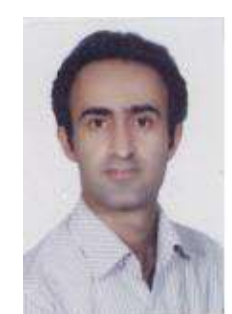

Mohammad Saber Iraji received B.Sc in Computer Software engineering from Shomal university, Iran, Amol ; M.Sclin industrial engineering (system management and productivity) from Iran, Tehran and M.Sc2 in Computer Science. Currently, he is engaged in research and teaching on Computer Graphics, Image Processing, Fuzzy and Artificial Intelligent, Data Mining, Software engineering and he is Faculty Member of Department of Computer Engineering and Information Technology, Payame Noor University, I.R. of Iran.

How to cite this paper: Mohammad Saber Iraji,"Fuzzy Agent Oriented Software Effort Estimate with COCOMO", International Journal of Intelligent Systems and Applications (IJISA), vol.7, no.8, pp.18-29, 2015. DOI: 10.5815/ijisa.2015.08.03 